\title{
HOUSEHOLD STORAGE OF FRUITS AND VEGETABLES
}

FRUIT AND VEGETABLE DIVISION MARKETING SERVICE

Published by authority of the Hon. James G. Gardiner, Minister of Agriculture, Ottawa, Canada

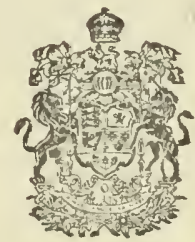


The life and nutritive value of fresh fruits and vegetables may be prolonged by proper storage. Good household storage becomes particularly important in these times of war when the economical use of food is so essential.

Undoubtedly it will be found surprising what can be accomplished by a little rearrangement of available storage space and close attention to a few simple rules such as, the careful selection of stock to be stored, care in handling and correct temperatures and humidity. 


\section{Household Storage of Fruits and Vegetables}

Household storage of fruits and vegetables is relatively easy, if a few simple rules are carefully followed. This bulletin is compiled therefore in as concise and adequate a manner as possible in an endeavour to assist the housewife who desires information in this regard.

\section{The Storage Room:}

A portion of the basement or cellar of any house may be adapted to the purpose of a storage room. This space should be selected in that portion of the basement which provides a double window leading directly outside, thus permitting the intake of fresh air and the escape of foul or stale air.

An earth floor is conceded to be the most satisfactory, but where concrete exists a covering of sand is recommended with an occasional sprinkling of water to maintain the humidity or moisture content of the air.

Partitions dividing the storeroom from the rest of the basement should be sheathed with lumber on both sides of the studding; good insulation is obtained by filling the partition space between the sheathing with dry sawdust, peat, or mill shavings.

A well made and close fitting door is essential, which when provided with a door stop permits temperatures to be regulated during subzero periods.

The containers for the vegetables should be constructed against the outside wall where cooler conditions exist, and these containers should have slatted sides and bottom to provide for ventilation. If possible, construction should be in a collapsible manner to facilitate cleaning.

Whitewash used on the walls makes for a sanitary room, and annually a solution of approximately $\frac{1}{4} \mathrm{lb}$. of copper sulphate to 1 gallon of water can be used as a cleanser and disinfectant. A good thermometer should be installed in every storage room.

\section{Selection of Specimens:}

All fruit and vegetables selected for winter storage should be well grown, fully mature, and free from damage caused by insects, disease, rough handling, mechanical injury, freezing and chilling. Great care must be exercised in grading and sorting the produce, to eliminate decayed or partly decayed specimens.

It is essential that all specimens be thoroughly dry and clean, since moisture allowed to remain on produce induces decay. During the storage period produce should be sorted regularly and defective specimens completely removed from the storage room, since refuse which is allowed to remain causes the contamination of sound stock. 
Samples of such products as apples, potatoes and turnips should be cut to determine internal injury. Apples are subject to such internal defects as railroad worm, bitter-pit, core flush, corky-core and water-core; potatoes with black-heart, mildew, blight and internal browning; turnips with brown-heart. Fruits and regetables affected with internal injury should not be stored.

\section{APPLES}

Selection of Varieties:

Only those varieties which have been established as suitable should be chosen for winter storage, such as: Spy, Baldwin, Russet, Stark, King, McIntosh, Snow, R. I. Greening, etc.

Fruit should be fully mature, and all green specimens avoided. To maintain a maximum of quality, appearance and condition, apples should be placed in storage immediately after harvesting. Allowed to remain outside in piles or in barrels in the sun and exposed to the weather, they are liable to unnecessary deterioration and a shorter storage expectancy.

\section{Care in Harvesting:}

Decay or infection from diseases can be prevented by avoiding finger nail scratches, skin punctures, and bruising caused by careless handling and the dropping of the fruit into baskets or bags. Sound fruit with unbroken skin is not susceptible to fungus infection. Once the skin is broken, however, the entrance of fungus or moulds is made possible, thus causing decay or breakdown. Stemless apples should be examined for broken skin in the stem-well.

\section{Storage Containers:}

Separate as to variety, apples should be placed preferably in slatted bushel crates, which allow for air circulation. Exceptional specimens for dessert purposes may be individually wrapped in paper. To reduce scalding to a minimum use shredded oil paper or oil wraps.

\section{Temperatures:}

Temperatures should be maintained as constant as possible, at approximately $33^{\circ}$ to $38^{\circ} \mathrm{F}$. Sudden changes are injurious and should be avoided. The maintenance of humidity from 80 to 85 per cent is considered good storage practice.

Should shrivelling be evident it is an indication that the humidity is low and this may be corrected by an occasional sprinkling of water on the floor of the storage room.

If moulds are in evidence then the opposite is the case, and the humidity probably is excessive, in which case a thorough ventilation of the storage room is recommended.

\section{Digging:}

\section{POTATOES}

Potatoes should be dug in fine weather if possible, and allowed to thoroughly dry before storing. Potatoes in a wet condition are very subject to decay. During the digging and drying process care should be taken to avoid damage from frost and chilling winds. 


\section{Position in Storage:}

Potatoes are best placed in a dark portion of the room, as light adversely affects the quality.

\section{Ventilation:}

Potatoes are best stored in crates, but when placed in piles or in bulk they should rest on a false floor, and against the wall upon which slats or racks have been nailed. Upright ventilators should be placed every few feet in the pile, and are made by nailing three 6 " boards together to form a V-shaped trough in which 1 " holes have been bored for air circulation. Such piles should not be more than $5 \mathrm{ft}$. high.

Insufficient ventilation tends toward the development of breakdown, button rot or black-heart. The accumulation of excess moisture encourages moulds and fungus diseases.

\section{Temperatures:}

Potatoes freeze at $29^{\circ}$, but will chill and sweeten if stored below $35^{\circ}$. Sprouting and wilting are induced at $41^{\circ}$ or over, which indicates that $36^{\circ}$ to $40^{\circ} \mathrm{F}$. is the most satisfactory storage temperature for potatoes.

\section{ONIONS}

Selection of Stock:

Onions should be dry and well cured before being placed in storage, and no field frost, sun scald or decay should be in evidence. Necks should not be thick; from $1^{\prime \prime}$ to $2^{\prime \prime}$ of the stem should be attached and well shrivelled.

\section{Containers:}

Crates or shallow trays are the most suitable containers for the storage of onions. They may also be stored in open mesh bags.

\section{Ventilation:}

Ventilation is just as important a factor in the storage of onions as is temperature, since the bulbs continually give off moisture, which must be removed.

\section{Temperatures:}

Satisfactory temperatures range from $33^{\circ}$ to $35^{\circ} \mathrm{F}$. and the best relative humidity is 65 per cent.

\section{Periodic Inspection:}

Careful periodic inspection and sorting should be practised throughout the storage period, for the removal of specimens developing decay, sprouting and root growth.

Onion refuse should be removed from the storage quarters to avoid contamination. 


\section{CABBAGE}

\section{Preparation for Storage:}

Specimens with heads that are hard and heavy are in prime condition for storage. Left in the field too long the heads will burst and become too crisp or brittle, while heads cut when soft or immature will wilt badly.

Before placing in storage, strip off outside wrapper leaves which are loose, as these interfere with ventilation which is one of the most important essentials in the storage of cabbage stock. Heads that are yellow or damaged by decay, frost, insect, or mechanical injury, should be sorted out and set aside for immediate use.

\section{Methods of Storing:}

One method of storing cabbage is to bring the heads into the storeroom with roots attached, and place these roots in moist sand on the floor with heads in an upright position as closely together as possible.

Another method is to cut the heads from the roots, leaving about two inches of shank attached, and place these trimmed heads on the side shelves of the storage with two tiers on each shelf.

A third method is to pile trimmed cabbage heads on the cellar floor in the form of a long pyramidical heap with a six or eight head base, and stack to one head at the top, extending pile to length desired.

\section{Temperatures:}

Cabbage heads should be well cooled before placing in storage. Good storage temperature for cabbage is $33^{\circ}$ to $37^{\circ} \mathrm{F}$.

\section{CAULIFLOWER}

\section{Preparation for Storage:}

Cauliflower may be stored for a considerable time by lifting each plant with root attached, leaves tied up over the head, and planting close together in moist sand or soil on the storage floor. If late plants are available they will keep in this manner until January or early in February.

It has been found that cauliflower cut slightly before reaching full maturity will keep better than fully matured heads.

\section{Temperatures:}

Temperatures of $33^{\circ}$ to $40^{\circ} \mathrm{F}$. have been found to be the most satisfactory for cauliflower. Living-room temperature cause the surface of the head to harden, turn brown, and become loose within a few days.

\section{CELERY}

\section{Inside Storage:}

Celery plants should be stripped of outside rough leaves, and roots left attached. Plants should then be set in moist sand or soil in boxes, crates, or together on the storage floor. Rows of plants should be placed eight inches apart, and individual plants set as close as possible together to form the row. 
Soil or sand should be moistened with water at intervals of ten days during the storage period, by means of a hose pulled between the rows, thus allowing the water to run out on the soil among the plant roots, without wetting the leaves.

Temperatures:

Celery can be stored in a room where the humidity is fairly high, approximating 85 per cent, but where there is no danger of condensation of the moisture. A good storage room temperature range is $33^{\circ}$ to $38^{\circ} \mathrm{F}$.

Outside Storage:

Celery may be stored outside in trenches. or pits, when it is imporant to keep the roots moist, the leaves dry, and to provide against freezing injury. Celery must have dry leaves, otherwise disease develops rapidly.

Trenches should be dug about the depth of the stalk, and a foot to sixteen inches wide, and should be located on a side hill or well-drained spot. Place plants upright in the trench with roots covered, and leave stalks uncovered until the leaves are touched by an early frost. This reduces their moisture content. Then cover with straw or leaves, then a layer of soil to a depth of 4-6 inches.

When ready to bring into the house for use from such storage trenches, place in cold water to bring out the frost and to freshen.

\section{SQUASH AND PUMPKIN}

Squash and pumpkin require different storage conditions than do most of the other vegetables. A warm, dry atmosphere with temperature around $50^{\circ}$ to $65^{\circ} \mathrm{F}$. will be found satisfactory for these vegetables. Therefore they may be stored in the attic, or some convenient room where temperatures are higher than the cellar.

They may be placed in crates or barrels, but preferably placed on shelves. Careful handling to avoid bruising and puncturing of the outer skin does much toward the avoidance of decay and breakdown.

\section{Selection of Specimens:}

\section{TOMATOES}

Tomatoes picked in a mature green condition will keep for a relatively long period under satisfactory storage conditions. Such green tomatoes must be sound and free from growth cracks, skin punctures, insect and freezing injury.

\section{Method of Storing:}

Each green tomato should be individually wrapped in paper (newspaper will do) and placed in a closed box or drawer.

Another method is to pull the vine before any signs of frost injury are apparent, and suspend the entire vine from the ceiling of the storeroom.

\section{Temperatures:}

Tomatoes stored in the above-mentioned manner should be maintained at a temperature of about $50^{\circ}$, and under favourable conditions will continue to ripen until Christmas. 


\section{BEETS, CARROTS, PARSNIPS, SALSIFY, TURNIPS}

These roots may be stored in a manner similar to potatoes, since they require the same relative temperature range, $33^{\circ}$ to $38^{\circ} \mathrm{F}$., and humidity. To avoid loss of crispness through evaporation, cover with sand. The storage humidity and condition of the roots should determine if and when the sand should be kept dry or slightly moist. If shrinking or shrivelling is evidenced, the sand should be moistened.

If boxes are used as storage containers, place a thin layer of sand at the bottom of each container and fill with alternate layers of vegetables and sand. If such roots are piled in heaps on the floor a covering of sand should be sufficient.

When drying beets for storage, twist tops off instead of cutting with a knife, as the latter method causes bleeding and results in loss of colour and often decay.

\section{SWEET POTATOES}

Sweet potatoes keep well in storage, but unlike most other roots they winter best in a temperature of $50^{\circ}$ to $60^{\circ} \mathrm{F}$., lower temperatures favouring rot development.

\section{Store Plenty of Vegetables Eat Them Freely and thus Maintain Good Health.}

"AT A GLANCE" STORAGE CHART

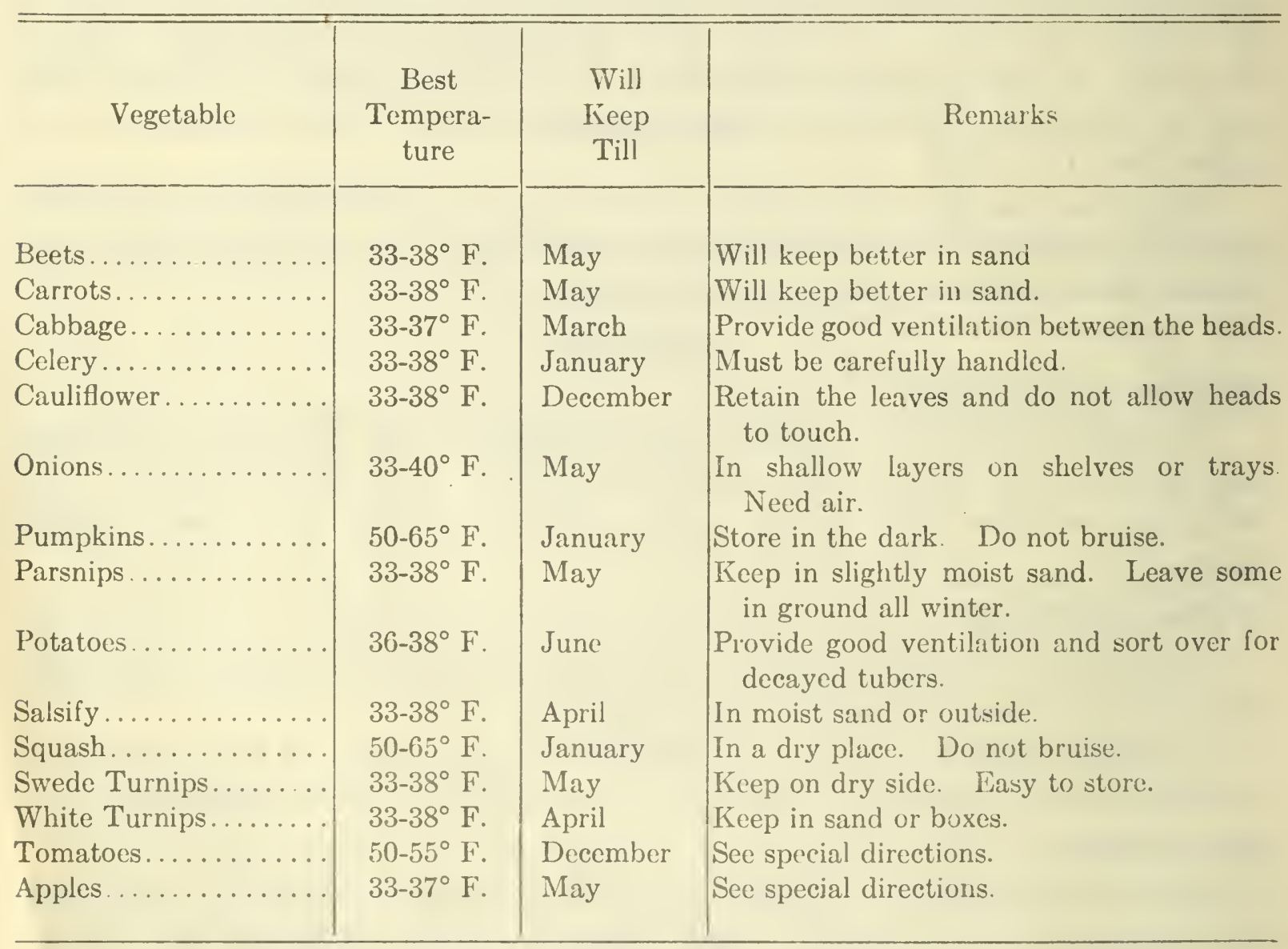

